\title{
Bioequivalence study of two formulations of flupirtine maleate capsules in healthy male Chinese volunteers under fasting and fed conditions
}

This article was published in the following Dove Press journal:

Drug Design, Development and Therapy

\section{Yanfang Liu \\ Hua Huo \\ Zhibo Zhao \\ Wenli Hu \\ Yujia Sun \\ Yunbiao Tang}

Technical Center for Clinical Pharmacy, Department of Drug Clinical Trail Management Agency, General Hospital of Shenyang Military Area Command, Shenyang, China
Correspondence: Yunbiao Tang Technical Center for Clinical Pharmacy, Department of Drug Clinical Trail Management Agency, General Hospital of Shenyang Military Area Command, No 83 Wenhua Road, Shenyang I 10840, China Tel +86 I 3372828008

Email tangyb99@163.com
Aim: This study developed a high-performance liquid chromatography-tandem mass spectrometry method to simultaneously determine the concentrations of flupirtine and its major active metabolite D-13223 in human plasma in order to assess the bioequivalence (BE) of two flupirtine maleate capsules among healthy male Chinese volunteers under fasting and fed conditions.

Materials and methods: There were two single-center, randomized, single-dose, open-label, laboratory-blinded, two-period, cross-over studies which included 24 healthy male Chinese volunteers under fasting and fed conditions, respectively. Plasma samples were collected prior to and up to $48 \mathrm{~h}$ after dosing. The concentrations of flupirtine and its major active metabolite D-13223 in plasma samples were determined by a validated method, that is, high-performance liquid chromatography coupled with a tandem mass spectrometry detector. Pharmacokinetic metrics of area from time zero to the last measurable concentration $\left(\mathrm{AUC}_{0-t}\right)$, area under the plasma concentration-time curve from administration to infinite time $\left(\mathrm{AUC}_{0-\infty}\right)$, and $\mathrm{C}_{\max }$ were used for $\mathrm{BE}$ assessment.

Results: Forty-eight healthy volunteers who met the criteria were enrolled and completed the study. According to the observation of vital signs and laboratory measurement, no volunteers had any adverse reactions. Under fasting condition, the geometric mean ratios (90\% CI) of the test/ reference drug for flupirtine were $103.0 \%(98.1 \%-108.2 \%)$ for $\mathrm{AUC}_{0-t}, 102.9 \%(98.2 \%-107.9 \%)$ for $\mathrm{AUC}_{0-\infty}$, and $97.0 \%(85.9 \%-109.5 \%)$ for $\mathrm{C}_{\max }$. Under fed condition, the geometric mean ratios $(90 \% \mathrm{CI})$ of the test/reference drug for flupirtine were $101.7 \%(98.4 \%-105.1 \%)$ for $\mathrm{AUC}_{0-\mathrm{t}}$, $101.6 \%(98.5 \%-104.8 \%)$ for $\mathrm{AUC}_{0-\infty}$, and $103.5 \%(94.7 \%-113.0 \%)$ for $\mathrm{C}_{\max }$. The difference between test and reference formulations, $\mathrm{T}_{\max }$, was not statistically significant. The $90 \% \mathrm{CIs}$ of the test/reference AUC ratio and $\mathrm{C}_{\max }$ ratio of D-13223 were also within the acceptance range for $\mathrm{BE}$ both under fasting and fed conditions.

Conclusion: The two formulations of flupirtine maleate capsule were bioequivalent (the test and the reference products) under fasting and fed conditions, and thus both can be used interchangeably in the clinical setting.

Keywords: flupirtine, D-13223, LC-MS/MS

\section{Introduction}

Flupirtine, ethyl- $N$-[2-amino-6-(4-fluoro-phenylmethyl-amino)pyridine-3-yl] carbamate, is a non-opioid analgesic without antipyretic or antiphlogistic properties. It acts centrally on $\gamma$-aminobutyric acid A receptors and the selective neuronal $\mathrm{Kv} 7$ potassium channel, ${ }^{1-3}$ thus offering a mechanism-based therapy for pain relief and normalization of muscle tension. ${ }^{4,5}$ 
A

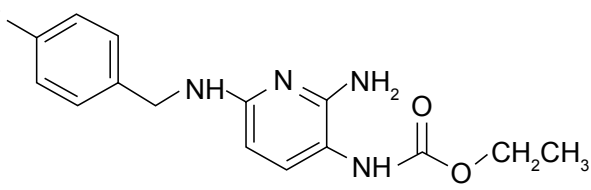

B

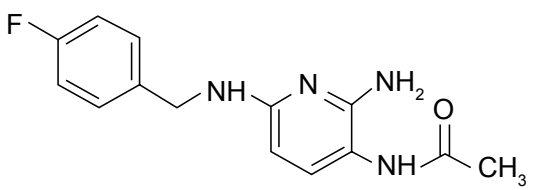

Figure I Flupirtine (A) and D-I3223 (B).

In patients with acute and chronic pain, flupirtine is clinically as efficient as weak opioids and NSAIDs, ${ }^{4-7}$ and its well-known neuroprotective properties make this drug a possible candidate for the treatment of Parkinson's, Alzheimer's, and CreutzfeldtJakob's disease and other neurodegenerative disorders. ${ }^{8-11}$ Clinical interest in flupirtine is growing in recent years.

As reported, flupirtine is a hydrophilic compound. It is completely absorbed from gastrointestinal tract with a bioavailability of $90 \%$ by oral route. ${ }^{12}$ One hundred milligrams of oral flupirtine in normal healthy volunteers reached a peak plasma concentration $\left(\mathrm{C}_{\max }\right)$ of $0.773 \mu \mathrm{g} / \mathrm{mL}$ at $1.6 \mathrm{~h}$. It gets equally distributed into both extra- and intravascular compartments. The apparent volume of distribution is $154 \mathrm{~L}$, half-life is $6.5 \mathrm{~h}$, and the clearance is $275 \mathrm{~mL} / \mathrm{min}$. Flupirtine is metabolized in liver to 4-fluorohippuric and $\mathrm{N}$-acetylated analog D-13223 (Figure 1) by peroxidase enzymes. The $N$-acetylated metabolite D-13223 retains $20 \%-30 \%$ of active parent compound. The two metabolites are further oxidized and then conjugated with glycine to form inactive metabolites. ${ }^{6,13}$ Seventy-two percent of the total dose administered appears in urine as parent drug and its metabolites, whereas $18 \%$ is excreted in feces. ${ }^{14}$

Flupirtine maleate capsule (Katadolon ${ }^{\circledR}$; AWD LTD, Hannover, Germany) has been effectively and safely used in Germany for 20 years. However, its use was limited due to its high price and poor cognition in China. The aim of this study was to develop a high-performance liquid chromatography coupled with a tandem mass spectrometry detector (LC-MS/MS) method to simultaneously determine the plasma flupirtine and its major active metabolite D-13223 concentrations, and thereby to assess bioequivalence (BE) for the same dose (100 mg) of two flupirtine formulations (generic drug and Katadolon) among healthy male Chinese volunteers under fasting and fed conditions.

\section{Materials and methods} Study protocol

Ethics committee of General Hospital of Shenyang Military Area Command approved the clinical study protocol and a no-objection letter was obtained from the China Food and Drug Administration. The study was performed in accordance with the Helsinki Declaration and Good Clinical Practice Guideline.

\section{Volunteers}

Forty-eight volunteers were judged eligible for enrollment by compliance with all the inclusion and exclusion criteria described in the protocol. The criteria were as follows: male, healthy, adult non-smokers or ex-smokers, aged 18-40 years with body mass indices $19-25 \mathrm{~kg} / \mathrm{m}^{2}$, clinically significant diseases were not captured in the medical history, and no evidence of clinically significant findings on physical examination and/or clinical laboratory evaluations (hematology, blood biochemistry, hepatic function, electrocardiogram examination, and urinalysis) was found. Participants were needed to have negative test results for human immunodeficiency virus, hepatitis B, and hepatitis C. All qualified participants signed an informed consent form prior to study commencement.

\section{Drugs and materials}

The test preparation of flupirtine maleate capsule (100 mg) was produced by the sponsor, PRC. The batch number was D150101. The reference preparation of katadolon $(100 \mathrm{mg})$ was produced by AWD pharma GmbH Co.KG, LTD, Hannover, Germany. The batch number was 1384 and was provided by the sponsor.

Flupirtine maleate, D-13223, stable-isotope internal standard (IS) flupirtine-d5(F-d5) and D-13223-d4(D-d4) (purity $99.9 \%, 99.5 \%, 99.5 \%$, and $98.0 \%$ respectively) were purchased from Toronto Research Chemicals Inc. (Toronto, Canada). Optima-grade methanol and acetonitrile were obtained from Fisher Scientific (Fairlawn, NJ, USA). All other chemicals and solvents were of analytical grade. Milli-Q water was obtained from a Millipore system (Millipore, Burlington, MA, USA).

\section{Study design}

This study consists of two independent clinical trials (fasting BE study and fed BE study), both of them were single-center, randomized, open-label, single-dose, laboratory-blinded, two-period, cross-over studies including 24 healthy male volunteers for each of the study. The same subject can participate in only one clinical trial.

\section{Fasting BE study}

Twenty-four volunteers were hospitalized in the study site the night before drug administration, and were randomized into two groups, group A and group B. After overnight fasting for at least $10 \mathrm{~h}$, group A was given test capsule, group B got 
the reference capsule (katadolon) in the morning. After the capsules were swallowed with $200 \mathrm{~mL}$ water, compliance of oral dosing was supervised by mouth and drug container inspection. Standard meals were provided 4 and $10 \mathrm{~h}$ after administration. Drinking of water was restricted $1 \mathrm{~h}$ prior to and after administration. After a 7-day washout, alternate capsule was administered and the experiment was repeated.

\section{Fed BE study}

The study was conducted with another 24 volunteers. It was similar to the fasting one except that both test and reference capsules were administered following a high-fat, high-calorie meal, which consisted of 150 calories protein, 250 calories carbohydrate, and 500 calories fat. Volunteers started the recommended meal $30 \mathrm{~min}$ prior to administration and finished in $30 \mathrm{~min}$. The standardized meals scheduled at the same time were the same in both of the two periods of the study.

\section{Blood sampling}

The venous blood samples of both fasted and fed treatments were collected at time intervals $(0,0.25,0.5,1.0,1.5,2.0$, 2.5, 3.0, 4.0, 6.0, 8.0, 12, 24, 36, and $48 \mathrm{~h}$ ) in separate 5-mL vacuum blood collection tubes. Blood samples were centrifuged at $1,500 \times g$ for $10 \mathrm{~min}$ and the plasma was separated and kept frozen at $-70^{\circ} \mathrm{C}$ until analysis.

\section{Analytical method}

The concentrations of flupirtine and its major active metabolite D-13223 were determined by LC-MS/MS based on the method of Chen et $\mathrm{al}^{15}$ with an API 3200 Q-Trap mass spectrometer equipped with a TurboIonSpray Ionization source. Chromatography was performed on an Agilent ZORBAX $(2.1 \times 150 \mu \mathrm{m} ; 5 \mu \mathrm{m})$, using a mobile phase of acetonitrile-water-ammonia $(55: 45: 0.1, \mathrm{v} / \mathrm{v} / \mathrm{v})$. The flow rate was $0.25 \mathrm{~mL} / \mathrm{min}$. The column temperature was maintained at $40^{\circ} \mathrm{C}$. The total LC analysis time per injection was $3.6 \mathrm{~min}$ with isocratic elution. An injection volume of $20 \mu \mathrm{L}$ was used for all samples.

\section{Sample preparation}

A $200 \mu \mathrm{L}$ aliquot of human plasma was added to $20 \mu \mathrm{L}$ ISs working solution and $20 \mu \mathrm{L}$ mobile phase and vortex for $30 \mathrm{~s}$. The sample mixture was extracted with $1 \mathrm{~mL}$ ethermethylene chloride $(3: 2, \mathrm{v} / \mathrm{v})$ and then vortex $30 \mathrm{~s}$ and centrifuged at $15,000 \times g$ for $10 \mathrm{~min}$. The supernatant was transferred to another tube and evaporated under a gentle stream of air at room temperature to dryness. The residue was reconstituted in $100 \mu \mathrm{L}$ mobile phase and vortex-mixed for $30 \mathrm{~s}$. An aliquot of $20 \mu \mathrm{L}$ was injected into the LC-MS/MS system for analysis.

\section{Method validation}

Flupirtine and D-13223 were detected and validated simultaneously by analyzing spiked plasma samples. According to relevant guidelines, ${ }^{16,17}$ validation included 1) selectivity, 2 ) accuracy and precision, 3) recovery and matrix effect, 4) the calibration curve, 5) lower limit of quantification, and 6) stability of analytes in spiked samples.

\section{Tolerability}

Tolerability assessment was primarily completed by monitoring volunteer's vital signs (blood pressure and heart rate). Time points were measured at baseline (predose) and at 2 and $48 \mathrm{~h}$ after administration. At baseline and after completion of the study, laboratory tests (hematology, blood biochemistry, hepatic function, and urinalysis) and electrocardiogram examination were performed.

\section{Pharmacokinetic study}

The pharmacokinetic (PK) parameters and statistical analysis were carried out by the validated statistical software WinNonlin 6.4 (Pharsight, Princeton, NJ, USA). The $\mathrm{C}_{\max }$ and time to $\mathrm{C}_{\max }\left(\mathrm{T}_{\max }\right)$ were obtained directly from the experimental data. The area under the plasma concentration-time curve from administration to infinite time $\left(\mathrm{AUC}_{0-\infty}\right)$ was calculated using the linear trapezoidal method: trapezoidal area from time zero to the last measurable concentration $\left(\mathrm{AUC}_{0-\mathrm{t}}\right)$, extrapolated to infinite time, by addition of the area obtained from the last measurable concentration divided by the terminal elimination rate constant $(\beta) ; \beta$ was estimated from the linear least-squared regression of the terminal phase of the log concentration-time profile. The apparent biological half-life $\left(\mathrm{t}_{1 / 2}\right)$ was calculated as $0.693 / \beta$. The parameters are represented with mean $\pm \mathrm{SD}$.

\section{Statistical analysis}

To evaluate the $\mathrm{BE}$ of the formulations, analysis of variance (ANOVA) was performed for log-transformed $\mathrm{C}_{\max }, \mathrm{AUC}_{0-\mathrm{t}}$, and $\mathrm{AUC}_{0-\infty} \cdot \mathrm{T}_{\max }$ was analyzed using a nonparametric approach. The evaluation of fixed period, sequence, and treatment effects was based on the Wilcoxon's rank-sum test. The log-transformed $\mathrm{C}_{\max }$ ratio, $\mathrm{AUC}_{0-\mathrm{t}}$ ratio, and $\mathrm{AUC}_{0-\infty}$ ratio were obtained for both formulations. ANOVA was performed by using the $F$ test. Two one-sided $t$-tests were used to obtain the probability of exceeding the limits of acceptance for BE $(80.00 \%-125.00 \%)$. If the log-transformed ratios of $\mathrm{C}_{\max }$ and $\mathrm{AUC}$ values of the two formulations were within a predetermined equivalence range, and their $90 \% \mathrm{CI}$ $P$-value was $<0.05$, the two formulations would have been considered bioequivalent. 


\section{Results}

\section{Bioanalytical method validation}

This study established an LC-MS/MS method for the determination of flupirtine and D-13223 in human plasma. Method specificity was demonstrated by comparing the multiple reaction monitoring chromatograms of blank samples with those of spiked samples. The retention times of flupirtine, D-13223, and the ISs were $2.71,2.17,2.69$, and $2.15 \mathrm{~min}$, respectively. No endogenous source of interference was observed at the retention time of the analytes and ISs.

The linear ranges were $0.01-2.00 \mu \mathrm{g} / \mathrm{mL}$ for flupirtine and $0.002-0.400 \mu \mathrm{g} / \mathrm{mL}$ for $\mathrm{D}-13223$ in human plasma. Typical equations of calibration curves were as follows:

$$
\begin{aligned}
& \text { Flupirtine: } y=1.07 \times 10^{-3} x+1.13 \times 10^{-4}, r=0.9994 \text {; } \\
& \text { D-13223: } y=4.17 \times 10^{-3} x+2.29 \times 10^{-4}, r=0.9985 \text {. }
\end{aligned}
$$

Intra/inter-day precision and accuracy were evaluated by using quality control (QC) samples at four levels in replicates $(n=6)$ by performing complete analytical runs on the same day and on three consecutive days. The intra-day precision was $<6.92 \%$ for each QC level of flupirtine and D-13223. The inter-day precision was $<9.26 \%$ for each QC level of flupirtine and D-13223. The accuracy as determined from QC samples was $-5.80 \%-3.31 \%$ for each QC level of flupirtine and D-13223, respectively.

Six blank matrices were extracted using the proposed extraction method and the standard solutions (equal to the low concentration quality control and the high concentration quality control) containing IS were spiked into the blank matrices after extraction. It indicated that the matrix effects had no practical effect on the quantification of flupirtine and D-13223.

The stability of flupirtine and D-13223 in human plasma was investigated under a variety of storage and process conditions. The results of the stability studies, summarized in Table 1, did not reveal any significant degradation under the conditions of the experiment.

\section{Pharmacokinetic and BE studies}

The LC-MS/MS method was employed for determining PK parameters of flupirtine and D-13223 in healthy male Chinese volunteers after administration of test and reference capsules at a dose of $100 \mathrm{mg}$. The mean plasma concentrationtime profiles of flupirtine and D-13223 under fasting condition are depicted in Figure 2A, and the mean plasma concentration-time profiles of flupirtine and D-13223 under fed condition are depicted in Figure 2B. The main PK parameters of flupirtine and D-13223 under fasting condition are

\begin{tabular}{|c|c|c|c|c|}
\hline \multirow[t]{2}{*}{ Storage conditions } & \multicolumn{2}{|c|}{ Flupirtine } & \multicolumn{2}{|c|}{ D-13223 } \\
\hline & 20.0 & 1,600 & 4.00 & 320 \\
\hline $\begin{array}{l}\text { Processed sample at room } \\
\text { temperature for } 6 \mathrm{~h}\end{array}$ & 17.0 & 1,367 & 3.79 & 297 \\
\hline RE \% & -14.8 & -14.6 & -5.17 & -7.19 \\
\hline $\begin{array}{l}\text { Unprocessed plasma sample } \\
\text { at room temperature for } 4 \mathrm{~h}\end{array}$ & 20.2 & $\mathrm{I}, 628$ & 4.23 & 345 \\
\hline RE \% & 0.92 & 1.77 & 5.75 & 7.92 \\
\hline Three freeze/thaw cycles & 18.2 & $\mathrm{I}, 430$ & 3.72 & 296 \\
\hline RE \% & -9.00 & -10.6 & -6.92 & -7.50 \\
\hline Long-term 44 days $\left(-70^{\circ} \mathrm{C}\right)$ & 20.1 & $\mathrm{I}, 567$ & 4.25 & 317 \\
\hline RE \% & 0.67 & -2.08 & 6.17 & -0.94 \\
\hline
\end{tabular}

Table I Stability of flupirtine and D- I3223 in human plasma $(n=3)$

Abbreviation: RE, relative error.

summarized in Table 2 and under fed condition in Table 3. The results of ANOVA test of two formulations for flupirtine and D-13223 under fasting and fed conditions are summarized in Table 4. The geometric mean ratios $(90 \% \mathrm{CI})$ of the test/reference capsules for flupirtine and D-13223 are summarized in Table 5.
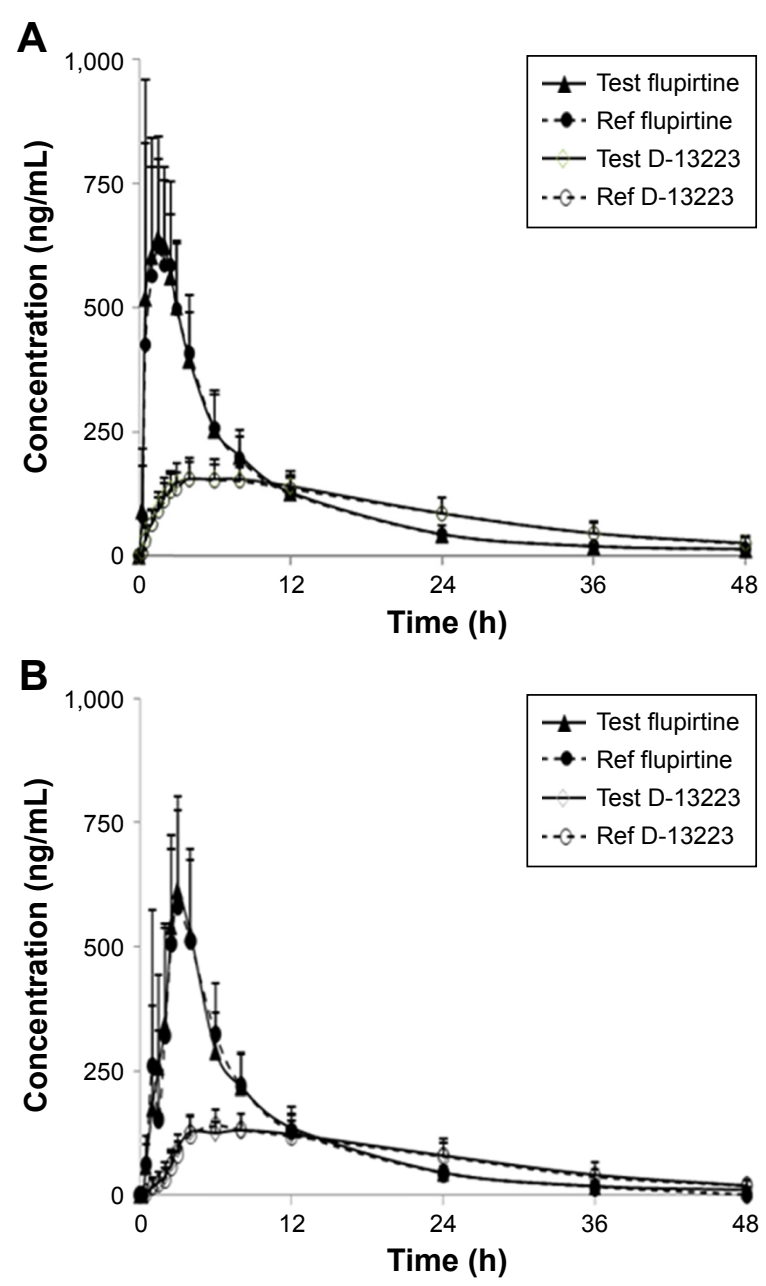

Figure 2 Mean plasma concentration-time profiles of flupirtine and D-I3223 under fasting (A) and fed (B) conditions after an oral dose of $100 \mathrm{mg}$ test capsule and reference capsule.

Note: Each profile represents the mean + SD of 24 volunteers. 
Table 2 Pharmacokinetic parameters for two formulations under fasting condition

\begin{tabular}{|c|c|c|c|c|}
\hline \multirow[t]{2}{*}{ Fasting } & \multicolumn{2}{|l|}{ Flupirtine } & \multicolumn{2}{|l|}{ D-13223 } \\
\hline & Reference & Test & Reference & Test \\
\hline $\mathrm{T}_{\max }(\mathrm{h})$ & $1.50 \pm 0.82$ & $1.52 \pm 0.73$ & $5.98 \pm 3.17$ & $5.54 \pm 2.76$ \\
\hline$C_{\max }(\mu g / m L)$ & $0.83 \pm 0.23$ & $0.82 \pm 0.27$ & $0.17 \pm 0.04$ & $0.18 \pm 0.01$ \\
\hline $\mathrm{AUC}_{0-\mathrm{t}}(\mu \mathrm{g} \times \mathrm{h} / \mathrm{mL})$ & $4.99 \pm 1.24$ & $5.12 \pm 1.18$ & $4.08 \pm 1.13$ & $4.16 \pm 1.06$ \\
\hline $\mathrm{AUC}_{0-\infty}(\mu \mathrm{g} \times \mathrm{h} / \mathrm{mL})$ & $5.21 \pm 1.25$ & $5.33 \pm 1.16$ & $4.60 \pm 1.43$ & $4.7 I \pm I .4 I$ \\
\hline$t_{1 / 2}(\mathrm{~h})$ & $7.64 \pm 1.57$ & $7.84 \pm 1.59$ & $13.4 \pm 3.12$ & $13.4 \pm 2.82$ \\
\hline
\end{tabular}

Table 3 Pharmacokinetic parameters for two formulations under fed condition

\begin{tabular}{|c|c|c|c|c|}
\hline \multirow[t]{2}{*}{ Fed } & \multicolumn{2}{|l|}{ Flupirtine } & \multicolumn{2}{|l|}{ D-13223 } \\
\hline & Reference & Test & Reference & Test \\
\hline $\mathrm{T}_{\max }(\mathrm{h})$ & $3.04 \pm 0.78$ & $2.87 \pm 0.64$ & $7.04 \pm 2.82$ & $6.30 \pm 2.29$ \\
\hline $\mathrm{C}_{\max }(\mu \mathrm{g} / \mathrm{mL})$ & $0.65 \pm 0.21$ & $0.67 \pm 0.18$ & $0.15 \pm 0.03$ & $0.15 \pm 0.04$ \\
\hline $\mathrm{AUC}_{0-\mathrm{t}}(\mu \mathrm{g} \times \mathrm{h} / \mathrm{mL})$ & $4.63 \pm 1.14$ & $4.76 \pm 1.14$ & $3.43 \pm 0.93$ & $3.50 \pm 1.16$ \\
\hline$A \cup C_{0-\infty}(\mu \mathrm{g} \times \mathrm{h} / \mathrm{mL})$ & $4.83 \pm 1.12$ & $4.96 \pm 1.13$ & $3.78 \pm 1.20$ & $3.83 \pm 1.38$ \\
\hline$t_{1 / 2}(\mathrm{~h})$ & $7.54 \pm 1.19$ & $7.72 \pm 1.29$ & $12.0 \pm 2.18$ & $11.4 \pm 2.20$ \\
\hline
\end{tabular}

Abbreviations: $\mathrm{AUC}_{0-\tau,}$, area from time zero to the last measurable concentration; $\mathrm{AUC}_{0-\infty}$, area under the plasma concentration-time curve from administration to infinite time.
The results show that under both fasting and fed conditions, there were no difference in interindividuals, interpreparations, and interperiods between test and reference capsules. The $90 \% \mathrm{CI}$ of the test/reference AUC ratio and $\mathrm{C}_{\max }$ ratio of flupirtine and D-13223 were within the acceptance range for $\mathrm{BE}$.

\section{Safety}

A total of 104 volunteers were screened and 48 volunteers were enrolled. No volunteer enrolled withdrew from the study, and both the formulations were well tolerated. No severe or unexpected adverse event (AE) was recorded except the laboratory examination, which returned to normal after 8 days without the use of any concomitant medication.

\section{Discussion LC-MS/MS method development and optimization}

Various methods are available for the determination of flupirtine alone or flupirtine along with its major active metabolite D-13223 in biological fluids, like determination of flupirtine and D-13223 by LC-MS/MS following deproteinization with cyanomethane in rat, ${ }^{18}$ liquid-liquid extraction with

Table 4 Results of ANOVA test of two preparations under fasting and fed conditions

\begin{tabular}{|c|c|c|c|c|c|c|}
\hline \multirow[t]{2}{*}{ Parameters } & \multicolumn{3}{|l|}{ Flupirtine } & \multicolumn{3}{|l|}{ D-13223 } \\
\hline & Interindividuals & Interpreparations & Interperiods & Interindividuals & Interpreparations & Interperiods \\
\hline \multicolumn{7}{|l|}{ Fasting } \\
\hline $\operatorname{Ln}\left(C_{\max }\right)$ & 0.56 & 0.67 & 0.71 & 0.18 & 0.08 & 0.11 \\
\hline $\operatorname{Ln}\left(A \cup C_{0-t}\right)$ & 0.80 & 0.31 & 0.96 & 0.60 & 0.40 & 0.32 \\
\hline $\operatorname{Ln}\left(A \cup C_{0-\infty}\right)$ & 0.83 & 0.31 & 0.98 & 0.71 & 0.32 & 0.23 \\
\hline \multicolumn{7}{|l|}{ Fed } \\
\hline $\operatorname{Ln}\left(C_{\max }\right)$ & 0.39 & 0.25 & 0.99 & 0.94 & 0.64 & 0.10 \\
\hline $\operatorname{Ln}\left(A \cup C_{0-t}\right)$ & 0.87 & 0.14 & 0.15 & 0.88 & 0.71 & 0.15 \\
\hline $\operatorname{Ln}\left(A \cup C_{0-\infty}\right)$ & 0.82 & 0.12 & 0.22 & 0.88 & 0.92 & 0.66 \\
\hline
\end{tabular}

Abbreviations: $A N O V A$, analysis of variance; $A \cup C_{0-\imath}$, area from time zero to the last measurable concentration; $A \cup C_{0-\infty}$, area under the plasma concentration-time curve from administration to infinite time.

Table 5 Statistical comparison of the two formulations

\begin{tabular}{|c|c|c|c|c|c|c|c|c|}
\hline \multirow[t]{2}{*}{ Dependent } & \multicolumn{4}{|l|}{ Flupirtine } & \multicolumn{4}{|l|}{ D-13223 } \\
\hline & Ratio_\% ref & Cl_90 lower & Cl_90 upper & Power & Ratio_\% ref & Cl_90 lower & CI_90 upper & Power \\
\hline \multicolumn{9}{|l|}{ Fasting } \\
\hline $\operatorname{Ln}\left(C_{\max }\right)$ & 97.0 & 85.9 & 109.5 & 0.92 & 105.5 & 101.5 & 109.7 & 1.00 \\
\hline $\operatorname{Ln}\left(A \cup C_{0-t}\right)$ & 103.0 & 98.1 & 108.2 & 1.00 & 102.4 & 98.7 & 106.2 & 1.00 \\
\hline $\operatorname{Ln}\left(A \cup C_{0-\infty}\right)$ & 102.9 & 98.2 & 107.9 & 1.00 & 102.6 & 99.2 & 106.1 & 1.00 \\
\hline \multicolumn{9}{|l|}{ Fed } \\
\hline $\operatorname{Ln}\left(C_{\max }\right)$ & 103.5 & 94.7 & 113.0 & 0.99 & 98.0 & 91.9 & 104.4 & 1.00 \\
\hline $\operatorname{Ln}\left(A \cup C_{0-t}\right)$ & 101.7 & 98.4 & 105.1 & 1.00 & 100.6 & 97.2 & 104.3 & 1.00 \\
\hline $\operatorname{Ln}\left(A \cup C_{0-\infty}\right)$ & 101.6 & 98.5 & 104.8 & 1.00 & 102.6 & 99.2 & 106.1 & 1.00 \\
\hline
\end{tabular}

Abbreviations: $A \cup C_{0-\imath}$, area from time zero to the last measurable concentration; $A \cup C_{0-\infty}$, area under the plasma concentration-time curve from administration to infinite time. 
diethyl ether-dichloromethane in humans, ${ }^{15}$ and methyl-tertbutylether in humans. ${ }^{19,20}$ Also, there are some investigations about flupirtine by high-performance liquid chromatography coupled with fluorescence derivatization (HPLC-FLD) in animals or humans. ${ }^{21-25}$ Based on literature survey, we developed an LC-MS/MS method for simultaneous quantification of flupirtine and D-13223 in human plasma, which compared with previous studies, ${ }^{15,19,20}$ was optimized in the plasma volume and sample processing without controlling the factors like $\mathrm{pH}$ and temperature. It also has an adequate linearity range and lower limit of quantitation compared with Kandasamy et al. ${ }^{18}$ Also compared to HPLC-FLD, like previous studies, ${ }^{21-25}$ the LC-MS/MS method has the advantage of high stabilization and is also time-saving. The LC-MS/ MS method used for simultaneous quantification of flupirtine and D-13223 provided the sensitivity, specificity, and high sample throughput required for PK and BE studies.

\section{BE studies}

In the present study, the $100 \mathrm{mg}$ katadolon (AWD pharma GmbH Co.KG, LTD, Hannover, Germany) was used as the reference product, not only because of its same active substance, strength, and route of administration to the test product but also because it was the first approved flupirtine preparation in the world and it has the complete and sufficient safety and validity data as the basis for the approved listing.

Healthy volunteers were selected under the eligibility criteria, which were set to ensure that only a subject population without accompanying diseases interfering with the conduct and scientific evaluation of the study were enrolled in the study. In addition, involving healthy volunteers alone would minimize risk to the volunteers' well-being. To perform the two one-sided test procedures for BE on log-transformed plasma flupirtine concentration data, with BE limits of 0.80 and 1.25 for $\mathrm{AUC}$ and $\mathrm{C}_{\max }$, alpha $=0.05$, and power $=80 \%$, the number of volunteers needed for the BE study was determined by means of CI, as formerly presented by Ou-Yang et al. ${ }^{23}$ In the present study, the intrasubject coefficient of variance obtained from the ANOVA for the flupirtine and
D-13223 are listed in Table 6. Hence, the number of volunteers in both fasting and fed studies ( 24 volunteers) ensured that this study had adequate power to confirm the statistical conclusions.

The selection of parent drug and active metabolite as the moieties to be measured for BE assessment fulfilled the US Food and Drug Administration requirements of primary metabolite(s), formed directly from the parent compound. The parent drug and active metabolite should be measured if they are both 1) formed substantially through presystemic metabolism (first-pass, gut wall, or gut lumen metabolism) and 2) contribute significantly to the safety and efficacy of the product. The results of metabolite data provided supportive evidence and further ensured the $\mathrm{BE}$ for generic and reference drugs.

Based on standard BE guidelines, ${ }^{26,27}$ the criterion for BE is the $90 \% \mathrm{CI}$ of the test/reference geometric means ratio that falls in the range of $80.00 \%-125.00 \%$ for both AUC and $\mathrm{C}_{\max }$. The results of the present study showed that the $90 \%$ $\mathrm{CI}$ of the test/reference ratios for $\mathrm{AUC}_{0-\mathrm{t}}, \mathrm{AUC}_{0-\infty}$, and $\mathrm{C}_{\max }$ of flupirtine were within the acceptance range for $\mathrm{BE}$ both under fasting and fed conditions.

Using Wilcoxon matched-pairs test on the original data, the difference between the $\mathrm{T}_{\max }$ values of the two (test and reference) products was not statistically significant. Also the D-13223 data further prove the equivalent conclusion.

Compared with the parameters in Ou-Yang et $\mathrm{al}^{23}$ and Guo et al, ${ }^{25}$ in our study the $\mathrm{C}_{\max }, \mathrm{AUC}_{0-\mathrm{t}}$, and $\mathrm{AUC}_{0-\infty}$ of flupirtine under fasting condition for the test drug were lower, but $\mathrm{T}_{\max }$ and $t_{1 / 2}$ were in alignment with them. The difference of $\mathrm{C}_{\max }, \mathrm{AUC}_{0-\mathrm{t}}$, and $\mathrm{AUC}_{0-\infty}$ between our study and Ou-Yang et $\mathrm{al}^{23}$ and Guo et $\mathrm{al}^{25}$ may have been caused by the different detector. However, the $\mathrm{T}_{\max }$ and $t_{1 / 2}$ in all these studies showed the same trend of flupirtine in healthy male Chinese. The PK parameters are summarized in Table 7.

\section{Food effects on bioavailability of flupirtine}

So far, no reports of PK of flupirtine under fed condition in Chinese have been found in China or abroad. In this study, the PK parameters of flupirtine and D-13223 were compared between fasting and fed conditions (data shown in Tables 2 and 3).

Table 6 The intrasubject coefficient of variance of flupirtine and D-I3223

\begin{tabular}{|c|c|c|c|c|c|c|}
\hline \multirow{2}{*}{$\begin{array}{l}\text { Intrasubject } \\
\text { (\%) }\end{array}$} & \multicolumn{3}{|l|}{ Flupirtine } & \multicolumn{3}{|l|}{ D-13223 } \\
\hline & $\operatorname{Ln}\left(C_{\max }\right)$ & $\operatorname{Ln}\left(A \cup C_{0-t}\right)$ & $\operatorname{Ln}\left(A \cup C_{0-\infty}\right)$ & $\operatorname{Ln}\left(C_{\max }\right)$ & $\operatorname{Ln}\left(A \cup C_{0-t}\right)$ & $\operatorname{Ln}\left(A \cup C_{0-\infty}\right)$ \\
\hline Fasting & 24.8 & 9.91 & 9.58 & 10.2 & 9.61 & 8.79 \\
\hline Fed & 18.0 & 6.67 & 6.23 & 12.5 & 7.26 & 7.46 \\
\hline
\end{tabular}

Abbreviations: $A \cup C_{0,-}$ area from time zero to the last measurable concentration; $A \cup C_{0-\infty}$, area under the plasma concentration-time curve from administration to infinite time. 
Table 7 Summary of flupirtine PK parameters in literatures

\begin{tabular}{llllllll}
\hline PK parameters & $\begin{array}{l}\text { Reference } \\
\text { literature }\end{array}$ & Method & $\mathbf{C}_{\max }(\mu \mathbf{g} / \mathbf{m L})$ & $\mathbf{T}_{\max }(\mathbf{h})$ & $\begin{array}{l}\mathbf{A U C}_{0-\mathrm{t}} \\
(\mu \mathbf{g} \times \mathbf{h} / \mathbf{m L})\end{array}$ & $\begin{array}{l}\mathbf{A U C}_{\mathbf{0 - \infty}} \\
(\mu \mathbf{g} \times \mathbf{h} / \mathbf{m L})\end{array}$ \\
\hline Test capsule & Our study $(\mathrm{n}=24)$ & LC-MS/MS & $0.82 \pm 0.27$ & $1.52 \pm 0.73$ & $5.12 \pm 1.18$ & $5.33 \pm 1.16$ & $7.84 \pm 1.59$ \\
Katadolon & Our study $(\mathrm{n}=24)$ & LC-MS/MS & $0.83 \pm 0.23$ & $1.50 \pm 0.82$ & $4.99 \pm 1.24$ & $5.21 \pm 1.25$ & $7.64 \pm 1.57$ \\
& $23(\mathrm{n}=24)$ & LC-FLD & $1.25 \pm 0.29$ & $2.0 \pm 1.2$ & $9.11 \pm 2.31$ & $9.62 \pm 2.29$ & $8.0 \pm 1.1$ \\
& $25(\mathrm{n}=10)$ & LC-FLD & $1.08 \pm 0.30$ & $1.7 \pm 0.8$ & $8.41 \pm 1.62$ & $8.97 \pm 2.00$ & $8.85 \pm 2.15$ \\
\hline
\end{tabular}

Abbreviations: $A \cup C_{0-1}$, area from time zero to the last measurable concentration; $A \cup C_{0-\infty}$, area under the plasma concentration-time curve from administration to infinite time; LC-FLD, liquid chromatography coupled with fluorescence derivatization; LC-MS/MS, high performance liquid chromatography coupled with a tandem mass spectrometry detector; PK, pharmacokinetic.

The $\mathrm{C}_{\max }$ of fasting and fed conditions were $0.83 \pm 0.23$ and $0.65 \pm 0.21 \mu \mathrm{g} / \mathrm{mL}$, respectively. The $\mathrm{T}_{\max }$ were $1.50 \pm 0.82$ and $3.04 \pm 0.78 \mathrm{~h}$, respectively. It is not difficult to find that the highfat diet affects the absorption rate of flupirtine, and the $\mathrm{T}_{\max }$ is prolonged, and the $\mathrm{C}_{\max }$ is reduced. The $\mathrm{AUC}_{0-\mathrm{t}}$ of fasting and fed conditions were $4.99 \pm 1.24$ and $4.63 \pm 1.14 \mu \mathrm{g} \times \mathrm{h} / \mathrm{mL}$, $\mathrm{AUC}_{0-\infty}$ were $5.21 \pm 1.25$ and $4.83 \pm 1.12 \mu \mathrm{g} \times \mathrm{h} / \mathrm{mL}$, respectively. The $\mathrm{AUC}_{0-\mathrm{t}}$ and $\mathrm{AUC}_{0-\infty}$ shows a little lower in absorption extent of flupirtine after meal. The results suggest that it is reasonable to take flupirtine in an empty stomach because of its faster absorption rate and complete absorption, which mean faster and better drug efficacy.

\section{Conclusion}

The study developed an LC-MS/MS method to simultaneously determine plasma concentrations of flupirtine and its major active metabolite D-13223, and the method was successfully applied to evaluate the BE of test flupirtine maleate capsules and katadolon among healthy male Chinese volunteers under fasting and fed conditions.

Based on the pharmacokinetic and statistical results of the study, we can conclude that the two formulations of flupirtine maleate capsule were bioequivalent (the test and reference product) under fasting and fed conditions, and thus both can be used interchangeably in the clinical setting.

\section{Acknowledgment}

We deeply thank the volunteers for their participation in this study.

\section{Disclosure}

The authors report no conflicts of interests in this work.

\section{References}

1. Klinger F, Geier P, Dorostkar MM, et al. Concomitant facilitation of GABA(A) receptors and $\mathrm{K}(\mathrm{V}) 7$ channels by the non-opioid analgesic flupirtine. Br J Pharmacol. 2012;166(5):1631-1642.
2. Kornhuber J, Bleich S, Wiltfang J, Maler M, Parsons CG. Flupirtine shows functional NMDA receptor antagonism by enhancing $\mathrm{Mg}^{2+}$ block via activation of voltage independent potassium channels. J Neural Transm (Vienna). 1999;106(9-10):857-867.

3. Raffa RB, Pergolizzi JV Jr. The evolving understanding of the analgesic mechanism of action of flupirtine. J Clin Pharm Ther. 2012;37(1):4-6.

4. Friedel HA, Fitton A. Flupirtine. A review of its pharmacological properties and therapeutic efficacy in pain states. Drugs. 1993;45(4): 548-569.

5. Harish S, Bhuvana K, Bengalorkar GM, Kumar TN. Flupirtine: clinical pharmacology. J Anaesthesiol Clin Pharmacol. 2012;28(2):172-177.

6. Devulder J. Flupirtine in pain management: pharmacological properties and clinical use. CNS Drugs. 2010;24(10):867-881.

7. Klawe C, Maschke M. Flupirtine: pharmacology and clinical applications of a nonopioid analgesic and potentially neuroprotective compound. Expert Opin Pharmacother. 2009;10(9):1495-1500.

8. Uberall MA, Mueller-Schwefe GH, Terhaag B. Efficacy and safety of flupirtine modified release for the management of moderate to severe chronic low back pain: results of SUPREME, a prospective randomized, double-blind, placebo and active-controlled parallel-group phase IV study. Curr Med Res Opin. 2012;28(10):1617-1634.

9. Otto M, Cepek L, Ratzka P, et al. Efficacy of flupirtine on cognitive function in patients with CJD: a double-blind study. Neurology. 2004; 62(5):714-718.

10. Sattler MB, Williams SK, Neusch C, et al. Flupirtine as neuroprotective add-on therapy in autoimmune optic neuritis. Am J Pathol. 2008; 173(5):1496-1507.

11. Schroder HC, Muller WE. Neuroprotective effect of flupirtine in Prion disease. J Drugs Today (Barc). 2002;38(1):49-58.

12. Abrams SM, Baker LR, Crome P, et al. Pharmacokinetics of flupirtine in elderly volunteers and in patients with moderate renal impairment. Postgrad Med J. 1988;64(751):361-363.

13. Methling K, Reszka P, Lalk M, et al. Investigation of the in vitro metabolism of the analgesic flupirtine. Drug Metab Dispos. 2009;37(3): 479-493.

14. Blackburn-Munro G, Dalby-Brown W, Mirza NR, Mikkelsen JD, Blackburn-Munro RE. Retigabine: chemical synthesis to clinical application. CNS Drug Rev. 2005;11(1):1-20.

15. Chen X, Zhong D, Xu H, Schug B, Blume H. Simultaneous determination of flupirtine and its major active metabolite in human plasma by liquid chromatography-tandem mass spectrometry. J Chromatogr B Biomed Sci Appl. 2001;755(1-2):195-202.

16. FDA. Guidance, Compliance \& Regulatory Information (Drugs). 2001. Available from: http://www.fda.gov/Drugs/GuidanceComplianceRegulatoryInformation/Guidances/default.htm. Accessed October 18, 2017.

17. SDA. [Chemical agent preparation Bioavailability and biology. Technical guidelines for equivalence research]. 2005. Available from: http://www. sda.gov.cn/gsz05106/08.pdf. Accessed November 13, 2017.

18. Kandasamy K, Gowdra VS, Nammalvar H, Govindarajan AK. Bioanalytical method development, validation and quantification of flupirtine maleate in rat plasma by liquid chromatography-tandem mass spectrometry. Arzneimittelforschung. 2011;61(12):693-699. 
19. Scheuch E, Methling K, Bednarski PJ, Oswald S, Siegmund W. Quantitative LC-MS/MS determination of flupirtine, its N-acetylated and two mercapturic acid derivatives in man. J Pharm Biomed Anal. 2015;102:377-385.

20. Siegmund W, Modess C, Scheuch E, et al. Metabolic activation and analgesic effect of flupirtine in healthy volunteers, influence of the polymorphic NAT2, UGT1A1 and GSTP1. Br J Clin Pharmacol. 2014; 79(3):501-513.

21. Liu XM, Wang, L, Zhang Y, Jang XH. Pharmacokinetics and bioequivalence of sustained-release flupirtine maleate tablets in Beagle dogs. Chin $J$ Pharm Anal. 2012;32(10):1731-1735.

22. De Vito V, Lebkowska-Wieruszewska B, Owen H, Kowalski CJ, Giorgi M. Pharmacokinetic profiles of the analgesic drug flupirtine in cats. Vet J. 2014;202(2):309-313.

23. Ou-Yang HP, Liu J, Li RH, et al. Determination of flupirtine maleate in human plasma by HPLC-FLD and its bioequivalence. $J$ Cent South Pharm. 2013;11:30-33.
24. Narang PK, Tourville JF, Chatterji DC, Gallelli JF. Quantitation of flupirtine and its active acetylated metabolite by reversed-phase high performance liquid chromatography using fluorometric detection. J Chromatogr.1984;305(1):135-143.

25. Guo T, Liu LX, Xia DY, et al. Comparison of pharmacokinetics of flupirtine maleate between Chinese Korean and Han healthy volunteers. J Herald Med. 2012;31(12):1530-1532.

26. Chinese Pharmacopoeia Commission. The Guiding Principle of Bioavailability and Bioequivalence of pharmaceutical preparations. Pharmacopoeia of the People's Republic of China. 2015;9011: 356-362.

27. The European Agency for the Evaluation of Medicinal Products (EMA), Committee for Proprietary Medicinal Products (CPMP). Note for Guidance on the Investigation of Bioavailability and Bioequivalence. CPMP/EWP/QWP/1401/98 Rev.1. 2010.

\section{Publish your work in this journal}

Drug Design, Development and Therapy is an international, peerreviewed open-access journal that spans the spectrum of drug design and development through to clinical applications. Clinical outcomes, patient safety, and programs for the development and effective, safe, and sustained use of medicines are the features of the journal, which has also been accepted for indexing on PubMed Central. The manuscript management system is completely online and includes a very quick and fair peer-review system, which is all easy to use. Visit http://www.dovepress.com/testimonials.php to read real quotes from published authors.

Submit your manuscript here: http://www.dovepress.com/drug-design-development-and-therapy-journal 